\title{
Duodenal perforation due to lollypop stick
}

\author{
Rupesh Keshri ${ }^{1}$, Digamber Chaubey ${ }^{1}$, *Sandip Kumar Rahul ${ }^{1}$
}

Sri Lanka Journal of Child Health, 2021; 50(4): 736-738

DOI: http://doi.org/10.4038/sljch.v50i4.9903

(Keywords: Child, Duodenum, Foreign body, Perforation)

\section{Introduction}

Isolated duodenal perforation in paediatric patients is rare and may have subtle presentation. We report a case of duodenal perforation secondary to ingestion of a lollypop stick in a two year old child which was detected late and presented with unique challenges during surgical management.

\section{Case report}

A two-year-old male presented to the emergency with abdominal distension since three days, refusal to feed and occasional bilious vomiting. There was no definite history of trauma or any significant illness in the recent past.

On examination, he weighed $12 \mathrm{~kg}$ and was dehydrated and tachycardic at presentation. Abdominal examination showed upper abdominal fullness with tenderness and guarding. X-ray abdomen and pelvis showed free air under the right dome of the diaphragm (Figure 1).

Routine blood investigations revealed a haemoglobin level of $10.4 \mathrm{~g} / \mathrm{dL}$ and a total leucocyte count of $12,400 / \mathrm{cu} \mathrm{mm}$. Abdominal ultrasonogram showed a moderate collection in the hepato-renal pouch and pelvis. After counselling the parents about the need for emergency surgery, exploratory laparotomy was performed. Bile mixed pus was seen in the peritoneal cavity. After doing peritoneal lavage, on further inspection we were surprised by the presence of a lollypop stick in the right sub-hepatic space with a perforation in the third part of duodenum (Figure 2).

The rest of the bowel and solid organs were normal on examination. We closed the perforation site after

1ndira Gandhi Institute of Medical Sciences,
Patna, Bihar, India
*Correspondence: sandeep.rahul65@gmail.com

https://orcid.org/ 0000-0002-9620-9305

(Received on 24 May 2020: Accepted after revision on 24 July 2020)

The author declares that there are no conflicts of interest.

Personal funding was used for the project.

Open Access Article published under the Creative Commons Attribution CC-BY CC (i) License introducing a $10 \mathrm{Fr}$ T-tube through the perforation site (Figure 3). Surgical wound was closed in layers after introducing a drain in the right sub-hepatic space.

In the postoperative period, on being shown the lollypop stick, mother recalled that she had given the child a lollypop five days ago and forgotten about it while doing her household work. Patient was symptom-free in the postoperative period; drain was removed on $5^{\text {th }}$ postoperative day and child was started on oral feeds after clamping the T-tube. Patient was discharged on full oral diet with a clamped T-tube neatly hidden in the dressing of the wound. T-tube was removed after two weeks when the patient came for follow-up in the outpatient's clinic as a day care procedure and child was sent home on the same day.

\section{Discussion}

Foreign body ingestion is common in young children because of their normal tendency to explore things by keeping them in the mouth ${ }^{1}$. Although most of these ingested substances can pass unimpeded through the gastrointestinal tract, some foreign bodies can obstruct or perforate the bowel necessitating surgical intervention. It has been observed that perforation occurs in less than $1 \%$ of all cases of foreign body ingestion ${ }^{2}$. These perforations can have delayed presentation because of the lack of a definite history, parents being unaware of the accidental ingestion of sharp objects by their children. Late presentation in perforation often leads to sepsis and a complicated clinical course which increases the morbidity and mortality in such cases. In our case, the mother had completely forgotten about the lollypop stick, and it being a non-radio-opaque material, could not be detected even on an X-ray of the abdomen. All these reasons can delay diagnosis and definite management of the patient.

Several investigators have observed that the ileocaecal and recto-sigmoid regions are the most commonly perforated sites in foreign body ingestion $\operatorname{cases}^{3,4}$. Duodenal perforation is less common $^{5}$. However, due to its retroperitoneal location, relative immobility, rigid nature, sharp angulations and deep transverse rugae, duodenum is a common site for entrapment of long and sharp foreign bodies ${ }^{6}$. Foreign bodies longer than $6 \mathrm{~cm}$ in 
length find it difficult to pass through the duodenal sweep and are therefore entrapped there ${ }^{7}$.

In our case, perforation had already taken place and the bowel at the margins of the perforation was oedematous and friable. Also, there was already evidence of pus in the right sub-hepatic space. Therefore, instead of closing the perforation site primarily, it was closed over a 10Fr. T-tube which gradually converted it into a controlled fistula, ensured low pressure at the site of perforation, reduced oedema and promoted healing of the local tissue. Oral feeds were started when there was evidence of normal bowel movement and T-Tube was clamped. Removal of T-tube was planned only when the tract matured and this was done after 2 weeks of discharge. Patient was asymptomatic thereafter on follow-up. We concluded that lollypop sticks can very rarely be the ingested foreign body in young children leading to possible perforation, entrapment or obstruction, each requiring prompt diagnosis and surgical management. Parents should be careful about things their young children eat or play with to lessen the risks of bowel perforation or any untoward complication.

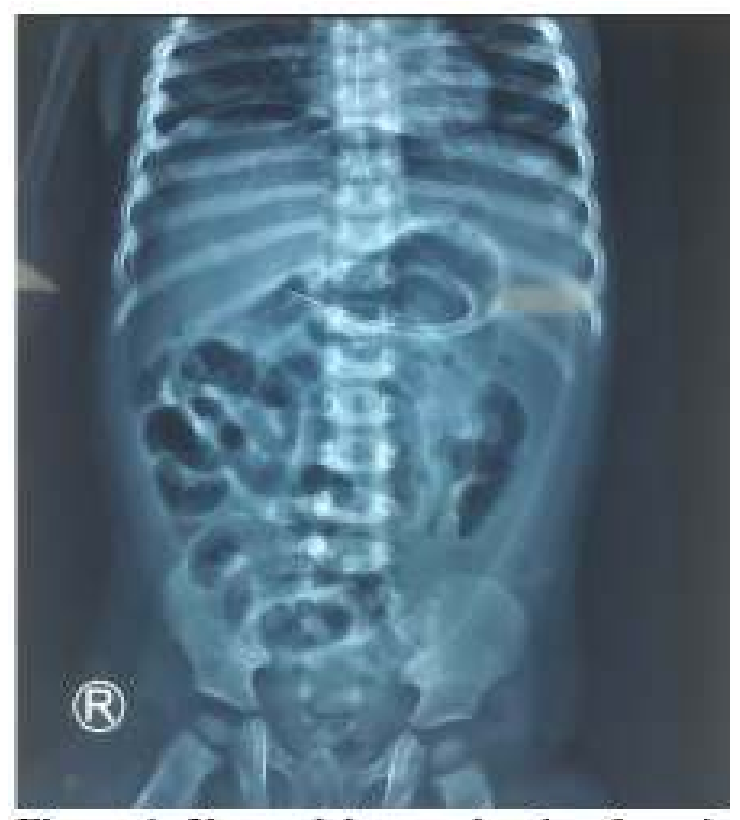

Figure 1: X-ray abdomen showing free air under right dome of diapgragm

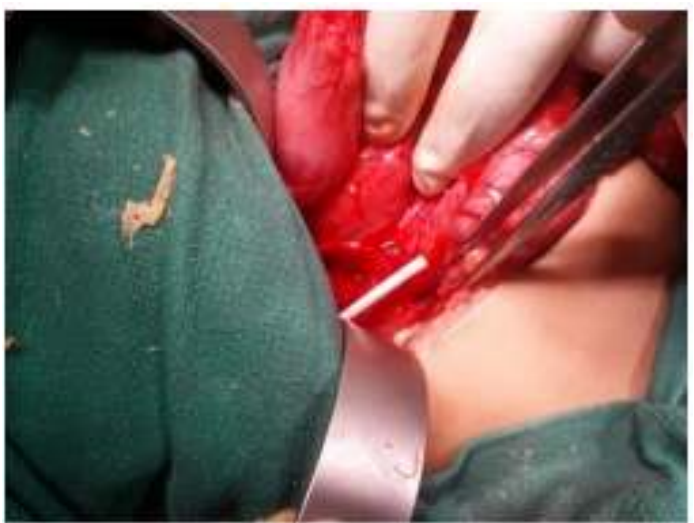

Figure 2: Perforation in third part of duodenum with lollypop-stick

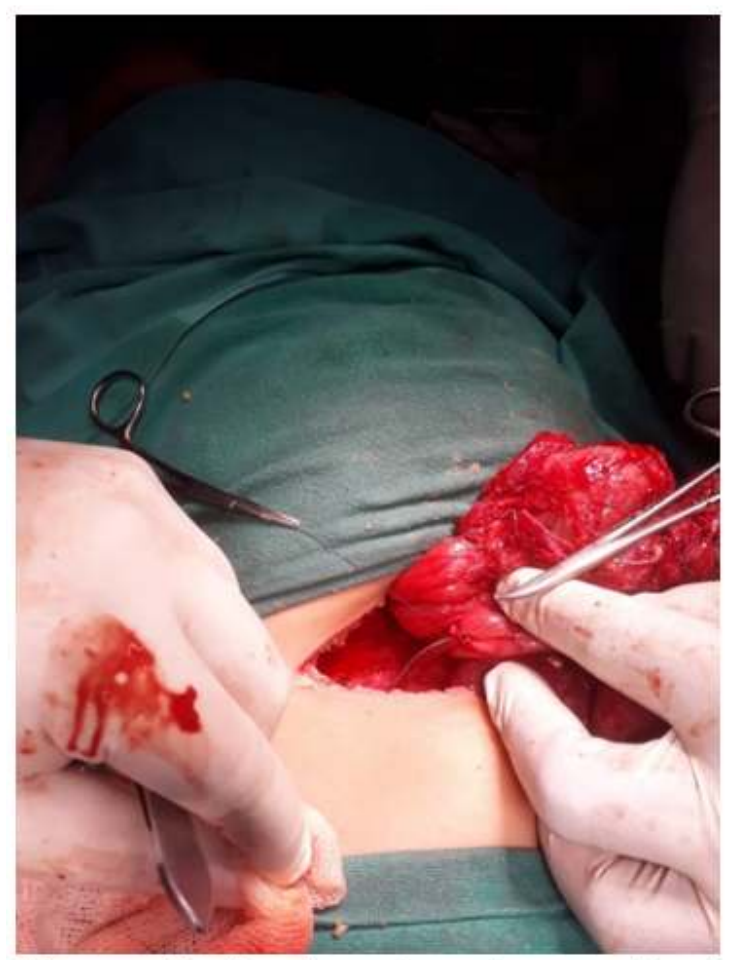

Figure 3: Perforation site repaired over a T-tube

\section{References}

1. Hernandez Anselmi E, Gutierrez San Roman C, Barrios Fontoba JE, Ayuso González L, Valdes Dieguez E, Lluna Gonzalez $\mathrm{J}$, et al. Intestinal perforation caused by magnetic toys. Journal of Pediatric Surgery 2007; 42:E13-6.

https://doi.org/10.1016/j.jpedsurg.2006.12. 066

PMid: 17336176 
2. Velitchkov NG, Grigorov GI, Losanoff JE, Kjossev KT. Ingested foreign bodies of the gastrointestinal tract: retrospective analysis of 542 cases. World Journal of Surgery 1996; 20:1001-5.

https://doi.org/10.1007/s002689900152

PMid: 8798356

3. Pinero Madrona A, Fernandez Hernandez JA, Carrasco Prats M, Riquelme Riquelme J, Parrila Paricio P. Intestinal perforation by foreign bodies. European Journal of Surgery 2000; 166:307-9.

https://doi.org/10.1080/110241500750009

140

PMid: 10817327

4. Kim MJ, Seo JM, Lee Y, Lee YM, Choe YH. An unusual cause of duodenal perforation due to a lollipop stick. Korean Journal of Pediatrics 2013; 56:182-5. https://doi.org/10.3345/kjp.2013.56.4.182 PMid: 23646057 PMCid: PMC3641315
5. Goh BK, Chow PK, Quah HM, Ong HS, Eu KW, Ooi LL, et al. Perforation of the gastrointestinal tract secondary to ingestion of foreign bodies. World Journal of Surgery 2006; 30:372-7. https://doi.org/10.1007/s00268-005-04902

PMid: 16479337

6. Chao HH, Chao TC. Perforation of the duodenum by an ingested toothbrush. World Journal of Gastroenterology 2008; 14:4410-2.

https://doi.org/10.3748/wjg.14.4410

PMid: 18666336 PMCid: PMC2731199

7. Eisen GM, Baron TH, Dominitz JA, Faigel DO, Goldstein JL, Johanson JF, et al. Guideline for the management of ingested foreign bodies. Gastrointestinal Endoscopy 2002; 55:802-6.

https://doi.org/10.1016/S00165107(02)704 07-0 